\title{
On the Benefits and Challenges of Blockchains for Managing Food Supply Chains
}

\author{
Katsikouli, Panagiota; Wilde, Amelie Sina; Dragoni, Nicola; Jensen, Henning Høgh
}

Published in:

Journal of the Science of Food and Agriculture

Link to article, DOI:

10.1002/jsfa. 10883

Publication date:

2021

Document Version

Peer reviewed version

Link back to DTU Orbit

Citation (APA):

Katsikouli, P., Wilde, A. S., Dragoni, N., \& Jensen, H. H. (2021). On the Benefits and Challenges of Blockchains for Managing Food Supply Chains. Journal of the Science of Food and Agriculture, 101(6), 2175-2181. https://doi.org/10.1002/jsfa.10883

\section{General rights}

Copyright and moral rights for the publications made accessible in the public portal are retained by the authors and/or other copyright owners and it is a condition of accessing publications that users recognise and abide by the legal requirements associated with these rights.

- Users may download and print one copy of any publication from the public portal for the purpose of private study or research.

- You may not further distribute the material or use it for any profit-making activity or commercial gain

- You may freely distribute the URL identifying the publication in the public portal 


\title{
ON THE BENEFITS AND CHALLENGES OF BLOCKCHAINS FOR MANAGING FOOD SUPPLY CHAINS
}

\author{
Panagiota Katsikoulii $^{1}$, Amelie Sina Wilde ${ }^{2}$, Nicola Dragoni ${ }^{1}$, Henning Høgh-Jensen ${ }^{2}$ \\ ${ }^{1}$ Technical University of Denmark, DTU Compute, Lyngby Denmark \\ ${ }^{2}$ Technical University of Denmark, DTU Food, Lyngby Denmark
}

\begin{abstract}
The expansion of the food industry, both on the national and the global stages, has resulted in complex collaborative networks and supply chains. The management culture adopted for food supply chains has an impact on the quality of the end product and the vitality of the involved businesses. In this report, we focus on the use of blockchain technology, and distributed ledgers in general, for managing supply chains in the food and agricultural sectors. We explore the challenges with which typical management systems are faced, such as food safety, food fraud and inefficient processes, as well as ethical aspects like fair trade, animal welfare and environmental impact of food production. The use of blockchain-based systems for managing a supply chain offers significant benefits, such as faster and more reliable traceability. Our analysis, involving Small and Medium Enterprises from Denmark, highlights that SMEs could benefit from blockchain-based systems that encourage fair trade and authenticity documentation, expose good practices and decrease managing costs.
\end{abstract}

This article has been accepted for publication and undergone full peer review but has not been through the copyediting, typesetting, pagination and proofreading process which may lead to differences between this version and the Version of Record. Please cite this article as doi: $10.1002 /$ jsfa.10883

This article is protected by copyright. All rights reserved. 
However, due to lack of important policies and standards and due to the limited understanding of the technology itself, its large-scale adoption is at the moment immature.

Keywords: Supply Chains, Case Studies, Blockchain Technology, Food Industry

\section{INTRODUCTION}

The global-scale expansion of the food industry in the modern age has resulted in complex collaborative networks that bring together producers, intermediaries and end consumers from great distances. Such networks are often referred to as food supply chains, a configuration set up for following a product from its primary ingredients, through its creation and trade, until its consumption.

Similar to supply chains for non-edible products, the management of food supply chains comprises of a number of roles (e.g., farmers, producers, dealers, supermarkets) and actions (e.g., farming monitoring, food quality certification, product transportation and packaging) that significantly affect the quality of the end product. The number of roles and actions, and the interactions between those, are numerous and complex. The high complexity of food supply chains, and the sensitivity of the handled products, require efficient and transparent management.

In recent years, blockchain technology has received increasing popularity, mainly due to the innovative story of Bitcoin (Nakamoto, 2008). Its innate features, such as immutability, distributed organization, consensus mechanisms, traceability and transparency, have made blockchains attractive to businesses and manufacturers for the management of their supply chains (for examples see (Appelhanz, 2016; Maouriyan, 2019; Lam, 2019)). Specific to food 
supply chains, there have been decent steps towards the use of blockchains (for examples see (Aung, 2014; Deloitte, 2019 - online)), showcasing the benefits in terms of ensuring food quality, fraud prevention and origin tracing.

In this work, we describe various challenges often encountered in typical food supply chains and comment on how they are currently handled (Section 2). We emphasize on the importance of managing a food supply chain in a secure and transparent manner, due to the sensitivity of the managed products. Next, we discuss where the adoption of blockchain can improve the management of food supply chains, how can a blockchain implementation assist in establishing better management with regards to the issues discussed in Section 2, and most importantly, the challenges and open problems that need to be addressed so that distributed ledger solutions (such as blockchains) become the natural choice in the food and agri-cultural sector (Section 3). In Section 4 we present five use cases from the Danish Food Industry, showcasing the various requirements SMEs have with regards to managing their supply chains, the challenges they face and how (and if) blockchain based supply chains could help them address such challenges. Finally, we present a summary of our findings and conclusive remarks in Section 5.

\section{CHALLENGES}

The increased length and complexity of supply chains often lead to a decrease in traceability and thus to enhanced vulnerability, as compliance with certain standards can be violated. In this section, we describe such and related challenges encountered in typical food supply chains. 


\subsection{Food Safety}

Food safety needs to be ensured on every step of the product life cycle, a process often referred to as the farm-to-fork approach. In order to maintain high levels of food safety, efficient food control systems and anyhow aligned standards must be established both from the governmental side as well as on operational level.

The inter-governmental Codex Alimentarius is an international collection of aligned standards that aims to target the challenge of different food inspection and certification systems from importing and exporting countries (Codex Alimentarius - online). Another organization is the Global Food Safety Initiative, a business driven organization which recognizes a number of certification programs that meet certain requirements and therewith supports retailers and other buyers to select suppliers that provide certificates by trustworthy operating certifiers (GFSI Certification - online). Even though it can be a challenge for companies to keep up with the deviating standards in different countries, it can be seen that professional strategies are in place.

In general, food products today are considered safer than ever before in history. However, this might not hold true for all countries, especially in developing countries with less established surveillance systems.

\subsection{Food Authenticity and Food Fraud}

Food fraud constitutes a problem from several perspectives. It causes loss of trust of the consumers into their food products. Moreover, it is a major issue in the business to business trade chain, as it leads to unfair competition and it is a threat for brand reputation, which can 
have massive long-term economic consequences for an affected company or even country. It can be seen on the food fraud database of the European Union that adulteration incidents in food products are regularly discovered ${ }^{2}$.

Clear definitions of food product specifications are particularly important in order to detect deviations that can be caused by very versatile forms of food fraud. At this moment, a comprehensive definition is challenging, as food fraud can be perpetrated in different ways. However, it is broadly accepted that food fraud covers cases where a violation of the food law is committed intentionally to pursue an economic gain through consumer deception. These cases include replacement or removal of valuable ingredients, addition of compounds to simulate a better quality, false misleading statements (like wrong geographical or botanical origin of a product) and also the deviation from declared manufacturing methods (Everstine, 2017).

Before one can control the compliance of a product to its authentic character, it is required that the specification is properly and clearly defined so that authentic and non-authentic products can be distinguished. It is a challenging and time consuming task to get unanimous agreement about unambiguous specification of food products to apply in different countries (Codex Alimentarius - online). Food authorities and business operators often rely on a diverse range of authenticity standards given by national and international law, governmental (e.g. Codex Austriacus), inter-governmental (e.g., Codex-Alimentarius) and non-governmental organizations (e.g. the International Organization for Standardization (ISO)). Due to the diverse range of standards, the analysis and documentation of authentic food is a complex task. 


\subsection{Fair Trade}

The "Guiding Principle on Business and Human Rights" is an international legal standard in the field of human rights ${ }^{3}$. These guidelines have an advisory character to states which are supposed to implement them in their national law. The states shall develop the so called

"National Action Plans" based on these guidelines, which enable to reveal gaps in legal regulations regarding transnational business and human rights; legally binding international standards protecting human rights from adverse effects of transnational corporations and other enterprises do not exist.

The guidelines are formulated around three pillars: (i) the state duty to protect human rights, (ii) the corporate responsibility to respect human rights and (iii) greater access to effective remedies, both judicial and non-judicial, for victims of corporate human rights abuse. Even though several states have published a national action plan, the effective implementation of the guidelines is often unsatisfactory. Very often very little attention is given to the third pillar, which often leads to victims of human rights violation be left without an effective remedy. Hence, a system where corporations that violate human rights are held accountable, is still in its infancy.

At the same time, several " fair trade" labels exist, implying that fair standards are respected. Terms like "fair" or "fair trade" are not legally protected, therefore some companies have developed their own concept which is often light in transparency and heavy in marketing ${ }^{4}$. However, labels like “fair trade international" are getting verified by the independent certifier FLOCERT, the first social certification body that obtained an ISO accreditation. 
For consumers, it is often impossible to understand the difference between the various fair trade labels set by companies and the labels that require a regular control of the farms by an independent certifier. Apart from a few serious initiatives, it can be seen that the implementation of fair-trade strategies is unfortunately still very immature.

\subsection{Environmental impact}

For food production, substantial amounts of land, water, fertilizer, pesticides and energy are required. Today's food supply chain creates $26 \%$ of anthropogenic greenhouse gas emissions (Poore, 2018). Despite the fact that sustainable food cultures are gaining much attention, labels about the environmental impact are rare. The establishment of labels that give meaningful information about food's environmental impact is complex. For example, apples from Europe that are consumed out of season need to be stored for a longer time period and therefore do not necessarily have a lower impact than apples that were imported from the southern hemisphere (e.g. New Zealand) (Canals, 2007). Moreover, the use of freshwater and fertilizers (containing nitrogen) have a major impact on the environment. Leach et al. (Leach, 2016) proposed a comprehensive environmental-impact food label that assesses a food product's sustainability in terms of energy, nitrogen and water use.

However, the European Union Ecoboard does not support the development of EU Ecolabel criteria on food, drink and feed in the immediate future, since a feasibility study has shown that developing and verifying Ecolabel criteria for food would be complex, resource intensive and costly (EcoBoard - online). Nevertheless, farmers in the EU are encouraged to adopt agricultural methods or levels of production intensity that deliver positive environmental 
outcomes. On European level, however, it is discussed how to promote the so called "carbon farming", which aims to reduce CO2-fingerprints (EU Commission - online).

Although a variety of voluntary ecolabels exist, which partly also include animal welfare and organic farming criteria, the establishment of multi-criteria methodologies that allow correct and comparable calculations about the environmental impact of food products, poses a major challenge and no standards based on the European law exist.

\subsection{Animal Welfare}

Consumers are increasingly interested in the treatment of animals in farms and livestock facilities and have increased intention to buy a product for which welfare standard details are provided (Cornish, 2020). Apart from the distinction of organic and non-organic products and the compulsory labeling on animal welfare for table eggs, there is no EU-wide harmonized system of animal welfare standards for labeling purposes. The lack of legally protected terms regarding animal welfare standards gives very little motivation for producers to improve animal welfare from a financial point of view, since farmers cannot set themselves apart from competitors with an appropriate labeling. Unfortunately, such labels are not anticipated any time soon, at least on European level ${ }^{5}$.

\subsection{Inefficient processes}

Supply chains involve many different processes and activities (such as trading, auditing, enforcing regulations) that are highly inefficient in typical implementations. One reason for the inefficiency is the fact that such processes are only partially digitized, and often require manual administration and paperwork. Furthermore, information about multipartite activities 
usually resides redundantly in each party's local database, and is usually inaccessible to others. As a result, there is no single source of truth, but also, a lot of friction in the process of requesting such data. This alone is responsible for significant financial and complexity overheads in the industry. It is estimated that the cost from managing and conducting redundant operations within supply chains makes up a substantial percentage of the final cost of goods (Kamilaris, 2019; Alicke, 2010). Moreover, paper heavy settlement processes, the use of traditional databases and the involvement of several intermediaries, bear the risk that important information is getting lost among transactions and that illegal activities remain undiscovered.

The EU regulation 178/2002 instructs food business operators to a one step back one step forward traceability. It is, however, not specified how this rule must be implemented. Therefore, both digital and handwritten documentation can be accepted.

\section{WHAT BLOCKCHAIN CAN AND CANNOT DO (YET)}

The application of blockchain technology can provide a very attractive tool for building holistic solutions to many of the problems encountered in traditional food supply chains. Blockchain, however, cannot by itself overcome all limitations and solve every possible issue, as it is merely a database.

The key benefit from using blockchain-based management systems as opposed to traditional databases stems from the inherent properties of the technology. In this section we discuss how blockchains can improve and even strengthen and democratize the management of food 
supply chains, but also what are the existing complexities impeding the way for the technology to become the universal solution.

\subsection{Digitization and automation}

Blockchain technology offers the opportunity to bypass several required intermediaries and contribute to the instant and immediate collaboration between different parties. The fundamental motivation is the decrease of administration cost and complexity by sharing consistent and tamper proof information across the many, and often located at great distances, participants. It can contribute to minimizing transaction duration, data duplication, incompatibility, paperwork and communication overhead.

What is more, management of a supply chain with the use of a distributed ledger can motivate even the most old-fashioned partners of the supply chain to digitize their records. A draft published by the European Commission in $2018^{6}$ states that only 1 in 5 SMEs in the European Union are highly digitized. The use of blockchain technology requires a digital file system, which is stored in a distributed way and accessible by multiple parties along a supply chain, making the database failure-resistant, environmental friendly, easier to access and manage, and one step closer to a fully digitized industrial and financial world.

One existing limitation is that different blockchain networks are not necessarily compatible with each other, and no universal blockchain standards exist yet. This problem is known as lack of interoperability. For a holistic solution:

- we need interoperable software (or established communication) that unites services offered by different providers which use different technologies 
- everyone in a supply chain should be willing to share relevant data on the same digital ledger in order to unleash the full potential of the technology

It will be one of the major obstacles to inspire active cooperation between companies with different technological maturity on their data collection and the provision of meaningful information to the end customer. Thereby, it must be considered that in some areas where the raw material is harvested, the experience with technological devices might be less advanced and that no reliable internet infrastructure exists.

\subsection{Traceability}

Distributed ledgers have the innate ability to provide significantly more efficient traceability than traditional supply chain management systems. Among other benefits, this leads to better reaction time when dealing with e.g. food-borne disease outbreaks. For example, Walmart's implementation ${ }^{7}$ claims to reduce traceability from 7 days to approximately 2 seconds.

However, this promise can only hold true if certain requirements are satisfied, since in practice, very often, the documentation and traceability might not be the sole or the most limiting time factor. One example is the Enterohaemorrhagic Escherichia coli (EHEC) crisis in Germany in 2011, which led to 3842 disease cases and 53 deaths (EHEC, 2011 - online). The identification of EHEC allowed to conclude when people were infected, based on incubation time of two days. With regards to what caused the disease, tomatoes and cucumbers were mostly under suspicion, which caused financial losses to farmers from Spain. Finally, based on the documentation of one of the affected restaurant owners, sprout seeds from Egypt, grown in Germany, were identified as the cause of this epidemic. This case 
demonstrates that for a targeted and very fast recall of specific batches of products, not only the cause of a problem must be known, but also it must be ensured that exclusively the specific batches are affected. A supply chain documented in an immutable distributed database would indeed have helped to speed up the clarification process and protect companies’ reputation.

\subsection{Transparency}

One of the core potentials from applying blockchain technology on the food supply chain management is the increase of transparency. Transparent documentation on an immutable database can enable better and more reliable traceability. Apart from the faster reaction time in case of failures, the increased transparency could make business routinely easier by building up an authentication-confirmation network.

Data recorded on a blockchain database can be considered as more reliable than on a centralized database, since they cannot be manipulated after being entered in the system. However, the blockchain technology can obviously not protect against fraud attempts which have been initiated before the data were entered in the system. The non-compliance between the digital and physical product is a very vulnerable point of the system. Some countermeasures can be taken to make the system more temper proof:

- cryptographically signed certificates of e.g. organic farming, fair trade or compliance with IFS standards added to the digital ledger directly by independent third parties,

- the chemical/physical and biological properties of a food product by analytical methods are an integrated part of quality management systems and can be used for 
the authentication of organic production, determination of the geographical origin or the presence of pesticides in food products (Camin, 2017; Hakme, 2020),

- relevant data generated by IoT devices, integrated in the quality management processes, could also be shared in the digital ledger. One example are spectroscopic sensors in combination with multivariate data analyses. Those have been shown to be an efficient and rapid tool to detect e.g. adulteration in herbs and spices (Sorensen, 2016; Black, 2016). The comparison and validation of these "spectroscopic fingerprints" of raw material at different stages of the supply chain can be used for quality control, since deviations caused by e.g. dilution or exchange of the original material would be made visible.

- detailed mass balance documentation is an integrated part of e.g. an IFS standard certification. This documentation must include batches that were bought, used, discarded and how and to whom they were sold.

For some participants in the supply chain, like the end consumer, testing is limited to the sensorial analysis of a product (sight, smell, taste, touch and hearing). Specific QR codes can be used in order to reveal a manufacturer that fraudulently tries to imitate another brand by using a random label that resembles more or less the original one (Sengupta, 2014).

The increased transparency supported by a distributed ledger can help with the deployment of a trust framework established by the customer's themselves. Different participants in the supply chain can use the immutable database to provide a public evaluation for each other. The opportunity of building up a good reputation allows the differentiation from competitors 
and may increase the willingness of the end user to pay a premium price. Moreover, the risk of gaining bad reputation incentivizes fair play, since malicious and fraudulent activities can lead to long term economic consequences for a company (Malik, 2019). Participant visibility in the supply chain, in combination with reputation records and quality certifications, supports a trustworthy farm-to-fork strategy (Deloitte, 2019 - online).

The feedback that finally leads to building up the reputation can be critical if not performed in a respectful and meaningful manner. For example, it could create a proxy to the habits, interests, political or religious views of the participating individuals, which could be used fraudulently by malicious adversaries. Furthermore, the large mass of consumers is not an expert in food science; presenting sophisticated details without context and some basic education, may easily result in ill-founded outcries.

\subsection{Standardization and regulations}

Standardization is the key issue to be addressed regarding the decision of what shall and/or should be recorded on a blockchain. The task of deciding which subset of quality management data should be available and shared across supply chain actors but also across supply chains, is not a trivial one. The main concern is to identify which information is relevant and important for supporting a fair, sustainable and trustworthy market, without exposing business's competitive secrets.

As described in Section 2, there is no common denominator for all regions/countries that follow different regulations and standards. The inter-governmental Codex Alimentarius aims for a certain harmonization of standards since it simplifies the free movement of food 
products in the market. However, a full harmonization of standards for all traded commodities is probably illusionary. One argument that stands in the way is that businesses have the freedom to set their own quality standards. The products obviously need to comply with the governmental regulations that apply in a specific area, but it is an individual's choice which additional quality criteria a private company might demand from their suppliers.

Moreover, alignment of standards and regulations requires compromises. One of the fundamental principles of the "Treaty on the Functioning of the European Union" (TFEU) is the free movement of goods originating in Member States, and of goods from third countries which are in free circulation in the Member States. The acceptance of different standards was also an issue when the Transatlantic Trade and Investment Partnership (TTIP) was discussed in 2013. The "chlorinated chicken"8 became a symbol for European consumers' concerns in case TTIP would be enforced. Further examples could be listed, which describe issues that create skeptical and concerned consumers around the globe. However, an agreement like TTIP would imply that regulations and standards decided by democratically elected members in one country are valid for the products of consumers that have never voted for these members. Thus, TTIP was often criticized as "antidemocratic". It is not the purpose of this report to comment or evaluate these issues, however, these examples clearly illustrate the complexity that generic standardization or mutual acceptance of food standards is facing in practice.

The challenges connected with the existence of diverse regulations and standards for products that are united in the same supply chain can obviously not be targeted by the blockchain technology. Neither can the technology compensate for missing standards. However, the 
challenge of handling different standards should give reason to document the certificates as transparent as possible in order to understand to which quality criteria a product corresponds.

\subsection{Technical challenges}

Setting aside the known open problems of the blockchain technology (e.g., scalability, interoperability, transaction throughput, privacy), which are relevant to most applications, the application of the technology in supply chains introduces additional challenges.

Perhaps the most challenging issue is that data stored on the database is as good as the input, known as the Garbage In - Garbage Out problem. Therefore real life stakeholders and physical items need to be bound with unique digital identities. Moreover, these associations need to stay valid throughout the entire supply chain. The blockchain technology by itself, at this stage at least, cannot provide a comprehensive solution in linking physical objects with digital identities in trustworthy and resilient ways. Neither can any other type of database. The integration of IoT devices and the use of token-based incentives are promising directions to bridge this gap.

Another challenge of the technology is to architect an access control solution that suites the needs of all participants, offering granular control over what parts of the system should be available at which parties. Since blockchains are not suited for storing large amounts of data on-chain, the matter of off-chain storage management is an open question. The dilemma of keeping such information on a shared cloud platform or distributed, introduces a number of technical, legal and trust-related consequences that require extended research. 
Finally, modern supply chains span across various countries with different regulations and highly adopted solutions. It seems implausible to create a system that fits all possible use cases, thus investing in one solution shall not hinder organizations in connecting to another. When designing such systems, decisions have to be made with compatibility and scalability in mind.

\section{USE CASES FROM DENMARK}

More and more companies are nowadays exploring the potential of using a blockchain based system for managing their supply chain. Here, we present the challenges that Danish SMEs in the food industry are facing, and their requirements for managing documentation and the various interactions along their food supply chains.

None of the selected companies manage their supply chain using blockchain at the moment. Since all companies are placing food on the market, they are responsible to provide secure and authentic products. The aim is not to comment or evaluate the structure of their quality management, but rather to make a connection between the challenges they are facing and explore the potential for blockchain based solutions. In the following cases, $\mathrm{CH}$ indicates the discussed challenges and requirements, and BC the respective potential solutions and limitations.

TwistedLeaf $^{\mathbf{1}}$ is a start-up that brews organic alcoholic and non-alcoholic beverages from coffee leaves, which is a waste product of the coffee industry. Their main ingredient, the coffee leaves, is bought from farms in East Africa. 
CH1: Shipments of the coffee leaves are naturally international. Because of the physical distance between the brewers and the farmers, and due to the impossibility of visual inspection of the product by the interested party, a matter of trust arises. Consequently, verification that the product that is sent from the farmers is of the agreed quality and quantity is of utmost importance. Equally important is the guarantee that during shipment, the product has not been tampered with and has been taken care of.

BC1: A recent study has shown that it is possible to determine the aging, taxa and harvest period of coffee leaves using a spectroscopic sensor (Mees, 2018). This technique can analyze relevant quality parameters of the coffee leaves. A big advantage of spectroscopic methods lies in the fact that a new sample can be screened within a few minutes and even non-specialist personnel can undertake sample analysis (Wilson, 2001). These findings show the potential to integrate IoT devices into the supply chain management. A farmer can test a specific batch in East Africa and only if the analysis shows compliance with the demanded quality, validated perhaps through a consortium of participants on the product's supply chain on a blockchain, then the batch can be shipped. Another advantage of a blockchain based data management tool is that for each batch the acquired spectra are signed, timestamped and cannot be tampered with afterwards.

CH2: It is important that the coffee leaves are produced under fair and environmentally sustainable conditions.

BC2: Since there are no governmental regulations in effect at the moment, companies need to orientate on organizations and programs that support those who voluntarily agree on being in compliance with certain standards. However, an immutable database, accessible by various 
parties, could support the current situation. The organizations could for example add signed certificates which prove that the indicated collaboration really exists. Moreover, if all documented steps along a supply chain are successfully registered in a blockchain database, more reliable and timely estimations can be made about the environmental impact of the food products.

Centrarogeriet $\mathbf{A} / \mathbf{S}^{9}$ focuses on the smoking of salmon, which they provide to high-end consumption points in Denmark and major cities in Europe and Asia.

CH1: The company delivers smoked salmon to some of the world's most famous fine restaurants. Therefore, there is high interest in protecting the information about the product as tightly as possible. Details about the smoking process and the suppliers must stay private, within the supply chain.

BC1: A permissioned blockchain would restrict the view of the transaction log and would therefore be suitable for this case. The data is cryptographically signed and securely stored in the blockchain.

CH2: Due to the company's excellent reputation for producing smoked salmon of extraordinary high quality, there is a risk that other producers of smoked salmon copy the label of Centralrøgeriet in order to sell their product for a premium price.

BC2: The link between the digital and the physical identity of the product is indeed one of the biggest challenges in blockchain applications. Thankfully, analytical methods that give an indication for the geographical origin of a smoked salmon do exist (Sorensen, 2016). A 
special labelling using an individual QR-code for each batch, together with a precise mass balance documentation in a blockchain based database, can establish a more secure system.

WeDo Food ${ }^{10}$ involves a number of restaurants in Copenhagen and a central kitchen for the preparation of the cooked food offered at the restaurants. The products offered at the restaurants are primarily vegan or vegetarian salads, desserts and drinks.

$\mathrm{CH} 1$ : The key characteristic of this restaurant chain is the large number of suppliers, and the many products involved in the preparation of a salad. The products are inspected upon arrival at the restaurants. However, some parameters, such as the freshness of meat or possible contaminations, can not necessarily be adequately assessed. A transparent database, where the results of typical quality control points are listed, can be an enormous advantage.

BC1: Using a blockchain database can speed up the traceability process. This is particularly important for extreme (and rare) cases, like the outbreak of a food-borne disease. If the responsible authorities had access to a digital ledger which documents the whole supply chain, the investigation process would be relieved and accelerated. A limiting factor could be that all participants of the supply chain must agree to give the authorities the permission for access to blockchain database, if necessary.

CH2: High value products are on risk of being adulterated, such as extra virgin olive oil, commonly added to salads.

BC2: Countermeasures that can be conducted in order to decrease the risks stemming from cases where the digital identity does not comply with the physical one (such as certificates, 
analytical results, IoT devices, mass balance documentation) can benefit from being integrated into an immutable blockchain database. This could make it easier for restaurants to evaluate which suppliers are particularly trustful.

Eskelyst $^{11}$ is an organic farm occupied with the breeding, growing and selling of pigs, cows and lamb. The farm applies the so-called holistic management grazing system in order to improve the soil carbon sequestration. This requires the implementation of practices that improve the conversion of atmospheric $\mathrm{CO} 2$ into plant material and/or soil organic matter.

$\mathrm{CH} 1$ : The farm puts special effort into the reduction of their CO2-fingerprint. At the moment there is no European-wide system where such practices are rewarded in the form of a monetary payment, or property title (i.e. carbon credit).

BC1: Once a carbon farming scheme has been developed and established in the EU, a blockchain-based database can be beneficial towards a trustworthy and efficient way to manage the certificates and prove the farm's special efforts.

$\mathrm{CH} 2$ : The farm is growing animals in accordance with the requirements for organic farming. However, the conditions on this farm go beyond the usual standards. Unfortunately, such good practices cannot be communicated to the consumers since no relevant labels exist.

BC2: Although a blockchain-based database cannot compensate for the lack of a label for animal welfare standards, the use of blockchain could still help to make the production processes more transparent and inform the consumers about the extra efforts that are made in order to increase animal welfare. 
CH3: Some consumers appreciate these special farming conditions and are willing to pay a higher price. There is a risk that the label might be copied by other producers in order to obtain a premium price for ordinary products.

BC3: As with Centralrøgeriet, labeling using an individual QR-code for each batch together with a precise mass balance documentation in a blockchain based database might be the best solution in order to follow the products through the supply chain.

Einar Willumsen ${ }^{12}$ specializes on producing flavors and complete solutions (e.g., juice, syrup etc.) for the food industry within and outside Denmark.

CH1: A key challenge here is that flavors are high value products and vulnerable towards food fraud.

BC1: It would be helpful for companies with similar challenges to buy raw material from sources where certain information (such as certificates, analytical results, IoT device data, and mass balance documentation) would be documented in transparent immutable databases.

CH2: Quality certificates for the raw materials need to be administrated and regularly updated. Unfortunately, the specifications for authentic products are set down in a diverse range of regulations and standards. Due to all the different existing standards, the administration means a considerable workload.

BC2: Blockchain technology facilitates these processes to be more efficient. Certificates could be added directly by their issuers, for example, which would reduce redundant work. In a more advanced software version, a compliance guide could be integrated, which would make the regulatory aspect easier. 


\subsection{Discussion}

We raise the following three points with regards to the intelligence we gained from the interviews with the SMEs:

1. what are the current practices the SMEs follow for managing their supply chains,

2. what are the specific requirements in their businesses,

3. what would it take for the companies to adopt blockchain technology for managing their transactions with vendors/suppliers etc.

In the following paragraphs we summarize our findings.

Current Practices Most SMEs store their data locally on computers or use customized centralized databases. A number of cases still use pen and paper for registering their supplies and sales. Orders to suppliers or from traders are primarily placed via mail or calls.

Requirements Food industries are concerned with (i) incidents of food fraud from their suppliers, (ii) certificates and authentication documents that prove originality and quality, (iii) how to enforce fair-play among competitors, (iv) use sustainable practices within their company, (v) branding and increase of clientele, (vi) decrease of managing costs.

The analysis from this work and from (Gonczol, 2020) suggests that blockchain technology can assist the food industry to achieve a number of their requirements. In brief, the properties of immutability, transparency and traceability, make blockchain technology a natural database option for digitally managing documentation and registering entries in groups of multiple users that do not necessarily know or trust each other. When it comes to food, 
registration and storage of cryptographically signed authentication documents allow for a secure and safe environment in which food fraud can be decreased and caught. What is more, the adoption of blockchain technology is a motivator for companies to digitize their databases.

Blockchain Adoption From the interviews we conducted and the interaction with a large body of the industrial population, our feeling is that the industry is not ready to adopt the technology immediately. This is due to a number of reasons. Firstly, there is significant lack of knowledge and education on the subject. Secondly, there is suspicion with regards to the adoption of the technology, for example, if that were to happen independently and out of choice by every company and not as a standardized collective initiative supported by nationwide or international standards and regulations. It is therefore apparent the need for education and for standards and regulations of the use of the technology.

\section{CONCLUSIVE REMARKS}

Food safety, food authenticity, fair trade, environmental impact of food and animal welfare are major challenges within food supply chains. Smaller industrial use cases illustrate the potential of the blockchain technology as a solution to overcome some of these challenges.

As noted from our interviews with the Danish SMEs, the traditional supply chain management practices are heavily centralized and in many cases, non-digitized. As such, a lot of necessary certificates and authentication documents are subject to alteration, or very often, not timely updated. A lot of potential lies in the increased degree of traceability, but also the more efficient data management processes offered by the blockchain technology. 
In essence, our report highlights that:

- knowledge from a versatile range of fields like natural, social, ethical, economic, political science and jurisprudence, needs to be gathered in order to design the solutions that tackle the challenges encountered by current food supply chains,

- the design of the solutions is independent of the availability of a decentralized immutable database, and primarily lies on the development of policies and standards,

- a significant step needs to be taken towards the digitization of SMEs and their supply chains, as well as towards the familiarization of the general public with alternative database systems, such as a blockchain,

- with all the above in place, the integration of decentralized immutable databases in food supply chains can significantly support and advance their management.

\section{ACKNOWLEDGEMENTS}

The report was written on behalf of the project "Bottom-up blockchain-værdikæder i fødevaresektoren" (Bottom-up blockchain value chains in the food sector) granted by Industriens Fond. Our partners in the project are: Jesper Nørgaard Viemose, Casper Høgenhaven, Helle Nielsen-Elgaard, Ben Cahill and Marianne Boelskifte.

\section{REFERENCES}

1. Nakamoto S. Bitcoin: A peer-to-peer electronic cash system. Whitepaper; 2008. 
2. Appelhanz S, Osburg VS, Toporowski W, Schumann M. Traceability system for capturing, processing and providing consumer-relevant information about wood products: system solution and its economic feasibility. Journal of Cleaner Production. 2016 Jan 1;110:132-48.

3. Maouriyan N, Krishna AA. AQUACHAIN-water supply-chain management using distributed ledger technology. In2019 3rd International Conference on Computing and Communications Technologies (ICCCT) 2019 Feb 21 (pp. 204-207). IEEE.

4. Lam OW, Zhibin LE. Textile and apparel supply chain with distributed ledger technology (DLT). In2019 20th IEEE International Conference on Mobile Data Management (MDM) 2019 Jun 10 (pp. 447-451). IEEE.

5. Aung MM, Chang YS. Traceability in a food supply chain: Safety and quality perspectives. Food control. 2014 May 1;39:172-84.

6. Deloitte [Online]. Beefing up Blockchain. Available here: https://www2.deloitte.com/ie/en/pages/technology/articles/beefing-up-blockchain.html.

7. Codex Alimentarius [Online]. Available here: http://www.fao.org/fao-whocodexalimentarius/home/en/

8. GFSI Certification [Online]. Available here: https://globalfoodsafetyresource.com/gfsicertification/

9. Everstine K. Supply chain complexity and economically motivated adulteration. InFood Protection and Security 2017 Jan 1 (pp. 1-14). Woodhead Publishing. 
10. Poore J, Nemecek T. Reducing food's environmental impacts through producers and consumers. Science. 2018 Jun 1;360(6392):987-92.

11. i Canals LM, Cowell SJ, Sim S, Basson L. Comparing domestic versus imported apples: a focus on energy use. Environmental Science and Pollution Research-International. 2007 Jul 1;14(5):338-44.

12. Leach AM, Emery KA, Gephart J, Davis KF, Erisman JW, Leip A, Pace ML, D’Odorico P, Carr J, Noll LC, Castner E. Environmental impact food labels combining carbon, nitrogen, and water footprints. Food Policy. 2016 May 1;61:213-23.

13. EcoBoard [Online]. Opinion of the European Union Ecolabelling Board. Available here: https://ec.europa.eu/environment/ecolabel/documents/EUEB_position_on_food_final.pdf

14. EU Commission [Online]. Carbon Farming Schemes in Europe - Roundtable. Available here: https://ec.europa.eu/info/sites/info/files/food-farmingfisheries/events/documents/carbon-farming-schemes-roundtable-background_en.pdf 15. Cornish AR, Briley D, Wilson BJ, Raubenheimer D, Schlosberg D, McGreevy PD. The price of good welfare: Does informing consumers about what on-package labels mean for animal welfare influence their purchase intentions?. Appetite. 2020 May 1;148:104577.

16. Kamilaris A, Fonts A, Prenafeta-Boldú FX. The rise of blockchain technology in agriculture and food supply chains. Trends in Food Science \& Technology. 2019 Sep $1 ; 91: 640-52$.

17. Alicke K, Lösch M. Lean and mean: How does your supply chain shape up. McKinsey \& Company. 2010. 
18. EHEC [Online]. 2011. Available here: https://www.ncbi.nlm.nih.gov/books/NBK114499/

19. Camin F, Boner M, Bontempo L, Fauhl-Hassek C, Kelly SD, Riedl J, Rossmann A. Stable isotope techniques for verifying the declared geographical origin of food in legal cases. Trends in Food Science \& Technology. 2017 Mar 1;61:176-87.

20. Hakme E, Poulsen SS. Data Processing Approach for the Screening and Quantification of Pesticide Residues in Food Matrices for Early-Generation Gas Chromatography Time-ofFlight Mass Spectrometry. Brazilian Journal of Analytical Chemistry. 2020;7(26):51-77.

21. Sørensen S, Lund KH, Cederberg TL, Ballin NZ. Identification of Baltic Sea salmon based on PCB and dioxin profiles. Food Control. 2016 Mar 1;61:165-71.

22. Black C, Haughey SA, Chevallier OP, Galvin-King P, Elliott CT. A comprehensive strategy to detect the fraudulent adulteration of herbs: The oregano approach. Food Chemistry. 2016 Nov 1;210:551-7.

23. Sengupta S, Sarkar P. A Novel Approach towards Detection of Spoofed Manufacturer Identity under the Collaborative Frameworks of Mobile Computing and Product Specific QR Codes. International Journal of Security and Its Applications. 2014 Dec 30;8(6):245-60.

24. Malik S, Dedeoglu V, Kanhere SS, Jurdak R. TrustChain: Trust management in blockchain and IoT supported supply chains. In2019 IEEE International Conference on Blockchain (Blockchain) 2019 Jul 14 (pp. 184-193). IEEE.

25. Mees C, Souard F, Delporte C, Deconinck E, Stoffelen P, Stévigny C, Kauffmann JM, De Braekeleer K. Identification of coffee leaves using FT-NIR spectroscopy and SIMCA. Talanta. 2018 Jan 15;177:4-11. 
26. Wilson RH, Colquhoun IJ, Kemsley EK. Screening food products for authenticity using infrared spectroscopy. American laboratory (Fairfield). 2001;33(11):54-5.

27. Gonczol P, Katsikouli P, Herskind L, Dragoni N. Blockchain implementations and use cases for supply chains-a survey. Ieee Access. 2020 Jan 8;8:11856-71.

Footnotes:

${ }^{1}$ https://www.twistedleaf.dk/

${ }^{2}$ https://ec.europa.eu/knowledge4policy/node/5680_de

${ }^{3}$ https://www.ohchr.org/documents/publications/guidingprinciplesbusinesshr_en.pdf

${ }^{4}$ https://fairworldproject.org/international-guide-to-fair-trade-labels-2020/

${ }^{5}$ https://ec.europa.eu/food/animals/welfare/other_aspects/labelling_en

${ }^{6}$ https://ec.europa.eu/futurium/en/system/files/ged/digital_innovation_hubs_in_digital_europe _programme_final2_december.pdf

${ }^{7}$ https://www.hyperledger.org/resources/publications/walmart-case-study

${ }^{8}$ https://www.bbc.com/news/uk-47440562

${ }^{9}$ http://centralrogeriet.dk/

${ }^{10}$ https://wedogreens.com/

${ }^{11}$ https://okologi.dk/landbrug/klima/her-goeres-en-ekstra-klimaindsats/2017/11/eskelyst

${ }^{12}$ https://einarwillumsen.com/ 